\title{
Predictors of recovery in moderate to severe traumatic brain injury
}

\author{
Kadhaya David Muballe, MD, PhD, ${ }^{1}$ Constance R. Sewani-Rusike, MBChB, PhD, ${ }^{2}$ \\ Benjamin Longo-Mbenza, MD, PhD, DSC, ${ }^{3}$ and Jehu Iputo, MBChB, $\mathrm{PhD}^{2}$ \\ Departments of ${ }^{1}$ Neurosurgery, ${ }^{2}$ Physiology, and ${ }^{3}$ Public Health, Walter Sisulu University, Mthatha, Eastern Cape Province, \\ South Africa
}

\begin{abstract}
OBJECTIVE Traumatic brain injury (TBI) is a significant cause of morbidity and mortality worldwide. Clinical outcomes in TBI are determined by the severity of injury, which is dependent on the primary and secondary brain injury processes. Whereas primary brain injury lesions are related to the site of impact, secondary brain injury results from physiological changes caused by oxidative stress and inflammatory responses that occur after the primary insult. The aim of this study was to identify important clinical and biomarker profiles that were predictive of recovery after moderate to severe TBI. A good functional outcome was defined as a Glasgow Outcome Scale (GOS) score of $\geq 4$.
\end{abstract}

METHODS This was a prospective study of patients with moderate to severe TBI managed at the Nelson Mandela Academic Hospital during the period between March 2014 and March 2016. Following admission and initial management, the patient demographic data (sex, age) and admission Glasgow Coma Scale score were recorded. Oxidative stress and inflammatory biomarkers in blood and CSF were sampled on days 1-7. On day 14, only blood was sampled for the same biomarkers. The primary outcome was the GOS score-due to its simplicity, the GOS was used to assess clinical outcomes at day 90 . Because of difficulty in performing regular follow-up due to the vastness of the region, difficult terrain, and long travel distances, a 3-month follow-up period was used to avoid default.

RESULTS Sixty-four patients with Glasgow Coma Scale scores of $\leq 12$ were seen and managed. Among the 56 patients who survived, 42 showed significant recovery (GOS score $\geq 4$ ) at 3 months. Important predictors of recovery included antioxidant activity in the CSF (superoxide dismutase and total antioxidant capacity).

CONCLUSIONS Recovery after TBI was dependent on the resolution of oxidative stress imbalance.

https://thejns.org/doi/abs/10.3171/2018.4.JNS172185

KEYWORDS trauma; traumatic brain injury; oxidative stress; inflammatory changes; recovery

$\mathrm{T}$

Traumatic brain injury (TBI) is a significant cause of death and disabling neurological deficits. ${ }^{2,32} \mathrm{Al}-$ though the Glasgow Coma Scale (GCS) score is important in assessing the state of consciousness, ${ }^{48}$ it has been noted to have great limitations and inconsistencies when used in assessing survival and functional outcomes among patients with TBI.,15,51 Clinical outcomes in patients with TBI can be assessed using the Glasgow Outcome Scale (GOS) score. ${ }^{22}$ Although current management strategies take into account factors such as the admission GCS score, pupillary reactivity, age of the patient, mecha- nism of injury, ${ }^{20} \mathrm{CT}$ scan findings, ${ }^{30}$ intracranial pressure (ICP), and brain tissue oxygen tension $\left(\mathrm{PBO}_{2}\right)$, little or no information regarding the degree of ischemic cell damage, the level of oxidative stress imbalance, and inflammatory changes can be deduced from these parameters.

Oxidative stress is a disturbance in the equilibrium status of prooxidant/antioxidant systems and accounts for most of the negative consequences of secondary brain injury. The process of oxidative stress involves enhancement in the production of free radicals and strong oxidants as well as depletion of body stores of antioxidants following

\footnotetext{
ABBREVIATIONS AUC = area under the curve; BBB = blood-brain barrier; $\mathrm{Cl}=$ confidence interval; $\mathrm{GCS}=$ Glasgow Coma Scale; GOS = Glasgow Outcome Scale; $\mathrm{HR}$ $=$ hazard ratio; $I C P=$ intracranial pressure; $I \mathrm{~L}=$ interleukin; $\mathrm{MDA}=$ malondialdehyde; $\mathrm{PBO}_{2}=$ brain tissue oxygen tension; $\mathrm{ROC}=$ receiver operating characteristic; $\mathrm{SOD}=$ superoxide dismutase; TAC = total antioxidant capacity; TBARS = thiobarbituric acid reactive substances; TBI $=$ traumatic brain injury; TNF $\alpha=$ tumor necrosis factor- $\alpha$. SUBMITTED September 10, 2017. ACCEPTED April 5, 2018.
}

INCLUDE WHEN CITING Published online November 9, 2018; DOI: 10.3171/2018.4.JNS172185. 
TABLE 1. Inclusion and exclusion criteria

\begin{tabular}{|c|c|}
\hline Inclusion Criteria & Exclusion Criteria \\
\hline $\begin{array}{l}\text { Patients w/ moderate to severe } \\
\text { TBI (GCS } \leq 12) \text { in whom } \\
\text { neuromonitoring \& surgical } \\
\text { intervention were indicated }\end{array}$ & $\begin{array}{l}\text { Patients who died while still in the } \\
\text { accident \& emergency depart- } \\
\text { ment before admission }\end{array}$ \\
\hline $\begin{array}{l}\text { Patients w/ intracranial pathology } \\
\text { requiring surgical intervention } \\
\text { \&/or temporary CSF diversion } \\
\text { to reduce ICP }\end{array}$ & $\begin{array}{l}\text { Patients in whom neuromonitoring } \\
\text { was not done due to logistical } \\
\text { problems }\end{array}$ \\
\hline $\begin{array}{l}\text { Patients w/ informed consent } \\
\text { (from relatives) to participate } \\
\text { in the study }\end{array}$ & $\begin{array}{l}\text { Patients w/ no informed consent } \\
\text { due to refusal by relatives to } \\
\text { participate in the study }\end{array}$ \\
\hline
\end{tabular}

trauma or inflammation. Early after TBI, oxidative stress changes occur, leading to increased lipid peroxidation and decreased enzymatic antioxidant activities, which can affect clinical outcomes. ${ }^{16,31}$

The reactive oxygen species generated during oxidative stress imbalance cause neuronal damage, dysfunction of the blood-brain barrier (BBB), and brain edema in TBI. ${ }^{19}$ These reactive oxygen intermediates, including superoxide anions, hydroxyl radicals, hydrogen peroxide, and hypochlorous acid, cause oxidative damage to cellular proteins and nucleic acids in addition to lipid peroxidation. ${ }^{26}$ Lipid peroxidation results in the generation of free radicals including malondialdehyde (MDA) and 4-hydroxynonenal (4-HNE) or 2-propenol (acrolein), which can cause increased cell membrane permeability, brain edema, and neuronal damage. ${ }^{49,55}$ Termination of lipid peroxidation occurs in reactions involving lipid radicals with endogenous antioxidants.

TBI also induces an inflammatory response, with subsequent release of inflammatory mediators. Delayed or inadequate management of TBI may propagate an unregulated acute inflammatory response and put in motion a vicious cycle of inflammatory damage ${ }^{8,19,21,25,33,38,42,45,52,54,60}$ caused by inflammatory factors such as tumor necrosis factor $-\alpha(\mathrm{TNF} \alpha)$, interleukin (IL)-1 $\beta$, and IL-18, which are proinflammatory cytokines. The secretion of inflammatory cytokines, including IL- $1 \beta$, TNF $\alpha$, IL-6, and IL8 , which occurs early in TBI, causes the recruitment of leukocytes and increased secretion of nitric oxide during inflammation. ${ }^{9,39}$ These proinflammatory responses lead to a disruption of the BBB, neuronal tissue damage, and worsening of brain edema., ${ }^{1,17,41}$

The inflammatory process also involves secretion of antiinflammatory factors, including IL-6 and IL-10. IL-6 has a dual inflammatory role, with both antiinflammatory and proinflammatory effects. The antiinflammatory effect of IL-6 is through inhibition of the TNF $\alpha$ synthesis, promotion of release of soluble TNF $\alpha$ receptors, induction of the IL-1 receptor antagonist, and attenuation of oxidative stress. ${ }^{37,57}$ IL- 6 also promotes the release of prostaglandin E2, which stimulates IL-10 secretion. ${ }^{24}$ The neuroprotective effects of IL-6 occur through neuronal apoptosis, regulation of cytokine secretion, and maintenance of BBB integrity by inhibiting the expression of matrix metalloproteinase-9 in ischemic cells. ${ }^{14}$ IL-10 is an immunoregulato- ry protein produced by macrophages, dendritic cells, and B-lymphocyte cells - it exerts its antiinflammatory effect by limiting or inhibiting adaptive and innate immunity. Actions of IL-10 prevent downregulation of antiapoptotic protein $\mathrm{Bcl}-2$ in ischemic brain tissue and limit excitotoxic brain injury. ${ }^{3}$ Effects of IL-10 in cerebral ischemia lead to a reduction in volume of infarcted tissue and improvement in clinical outcomes. Low levels of IL-10 are associated with impaired antiinflammatory response and poor recovery in stroke patients. ${ }^{4}$ The antiinflammatory effect of IL-10 attained by limiting the production of TNF $\alpha$ and interferon- $\gamma$ may lead to a reduction in tissue destruction and limitation of tissue necrosis..$^{28,58,59}$

\section{Methods}

This was a prospective study of patients with moderate to severe TBI managed at the Nelson Mandela Academic Hospital in the Eastern Cape Province of South Africa during the period between March 2014 and March 2016.

At the accident and emergency department, neurological evaluation and radiological investigations including CT scans of the brain were performed. The patients requiring surgical intervention were then taken to the operating room, where surgical procedures such as burr holes for the insertion of external ventricular drain catheters, ICP probes, $\mathrm{PBO}_{2}$ probes (Licox), and craniotomy or craniectomy were performed in patients with intracranial mass lesions for decompression or evacuation of intracranial hematoma. Criteria for inclusion or exclusion from the study were defined (Table 1).

Postoperatively, the patients were admitted to the ICU, where ventilation, sedation, analgesia, and monitoring of the ICP, $\mathrm{PBO}_{2}$, and brain tissue temperatures were done. Daily blood and CSF samples were taken at 9:00 AM for evaluation of inflammatory and oxidative stress biomarkers from day 1 to day 7. The blood was again sampled for evaluation of the biomarkers on day 14 of follow-up. The serum and CSF total antioxidant capacity (TAC) and superoxide dismutase (SOD) levels were analyzed. The serum MDA levels were assessed using the thiobarbituric acid reactive substances (TBARS) assay, whereas serum inflammatory biomarkers, including IL-1 $\beta$, IL- 6 , and IL10 , were assayed using the BioLegend enzyme-linked immunosorbent assay (ELISA) method. The patients were reviewed at 2 weeks and 12 weeks, during which time the GOS score was assessed.

\section{Sample Collection and Storage}

The blood samples were collected by venipuncture into sterile vacutainer non-EDTA-containing tubes (Becton Dickinson). Following centrifugation of blood samples for 13 minutes at $3000 \mathrm{rpm}$, the supernatant (serum) was pipetted into vacutainer tubes. Aliquots were then placed into cryovials bearing the patient's name, date, and time of collection before storage at $-80^{\circ} \mathrm{C}$. The CSF samples were also pipetted into cryovials and stored at $-80^{\circ} \mathrm{C}$.

\section{MDA Assay by Evaluation of TBARS}

The OxiSelect TBARS assay kit for MDA quantitation (Cell Biolabs, Inc.) was used. Assay of MDA by the 


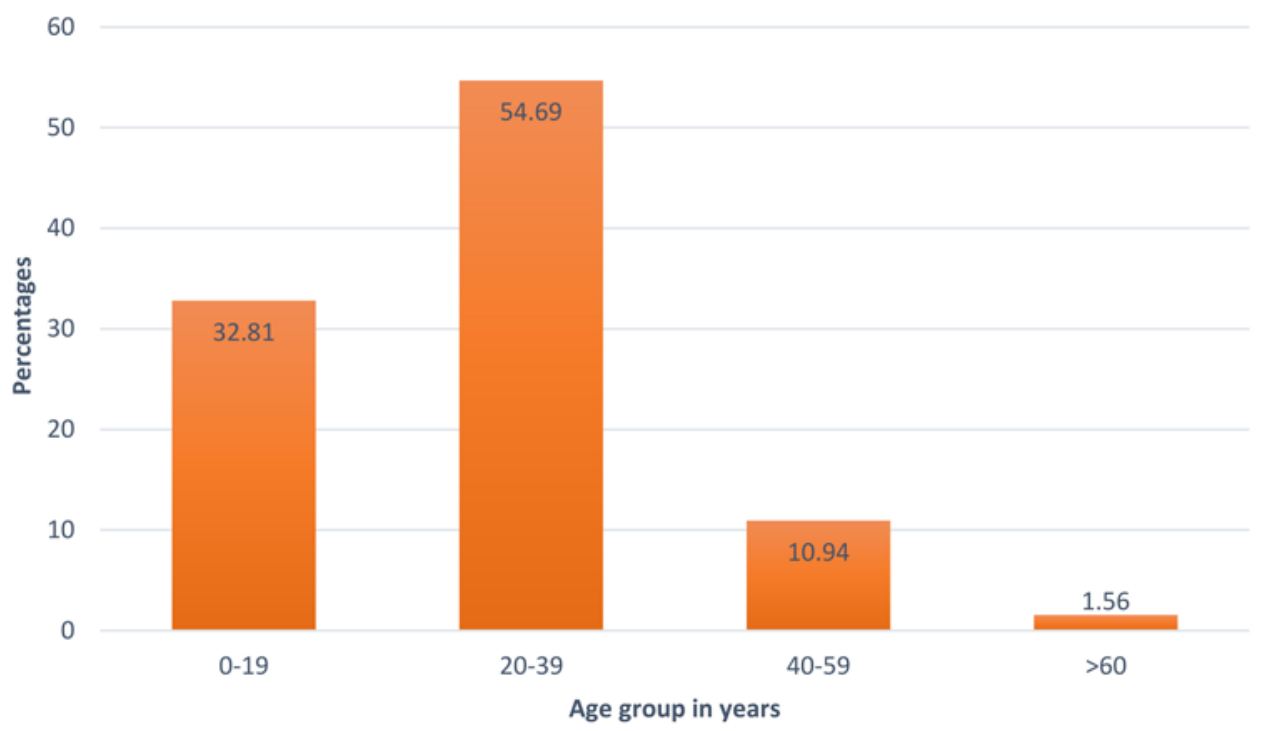

FIG. 1. Distribution of patients with TBI by age groups.

TBARS method is used to monitor lipid peroxidation. The procedure was performed per the manufacturer's specifications.

\section{SOD Assay}

A SOD assay kit manufactured by Cayman Chemical USA was used. The SOD assay kit uses tetrazolium salt for the detection of superoxide radicals generated by xanthine oxidase and hypoxanthine. One unit of SOD is the amount of enzyme needed to exhibit 50\% of dismutation of the superoxide radical. This assay measures all 3 types of SOD (Cu/Zn, Mn, and Fe SOD).

\section{TAC Assay by the Ferric-Reducing Antioxidant Power Method}

This method of evaluating the total antioxidant power assesses the ferric-reducing potential of the sample. During the procedure, inactivation of oxidants was done in a redox reaction by using reductants as the electron-donating antioxidants. Reduction of ferric tripyridyltriazone to a ferrous state occurs at a low $\mathrm{pH}$ to produce an intense blue color, which was measured by the change in absorbance at $593 \mathrm{~nm}$. The change in absorbance was directly related to the total reduction of the electron-donating antioxidants in the reaction.

\section{IL Assay}

IL-1 $\beta$, IL-6, and IL-10 assay was performed using BioLegend's ELISA MAX deluxe sets (ISO 9001:2008 and ISO 13485:2003; BioLegend, Inc.). The assay was performed per the manufacturer's specifications.

\section{Ethical Considerations}

Prior to initiation of the study, ethical and institutional approval was obtained from the Walter Sisulu University and the department of health according to the ethical guidelines of the Helsinki Declaration of 1975.

\section{Data and Statistical Analysis}

Data analysis was performed using SPSS version 23.0 for Windows (IBM Corp.). Univariate and multivariate logistic regression models including receiver operating characteristic (ROC) curves, Cox regression, and Kaplan-Meier estimates were used to identify the variables that were independently associated with survival and recovery.

\section{Results}

\section{Identification of Potential and Independent Predictors of Recovery of Cerebral Functional Status in Patients With Moderate to Severe TBI}

During the study, 64 patients with moderate to severe TBI were treated. The age of our patients ranged from 10 years to 62 years. The patient age group with the highest frequency of TBI was the age group 20-39 years (n $=35$ ), the intermediate frequency was in the age group $0-19$ years $(n=21)$, and the lowest frequency was in the age group 40-62 years $(n=8)$ (Fig. 1). Of the 64 patients, $65.6 \%(\mathrm{n}=42)$ sustained injuries from assaults, $21.9 \%(\mathrm{n}=$ 14) from motor vehicle accidents, $9.4 \%(n=6)$ from falls from heights, and $3.1 \%(\mathrm{n}=2)$ for other unclear reasons ("other") (Table 2).

Frequencies of pathology among the intracranial findings in 64 patients were as follows: subdural hematoma in $13(20.3 \%)$, extradural hematoma in 2 (3.1\%), brain edema

TABLE 2. Mechanism of injury and number of patients

\begin{tabular}{lcc}
\hline Mechanism of Injury & No. of Patients & $\%$ \\
\hline Assault & 42 & 65.6 \\
\hline Motor vehicle accident & 14 & 21.9 \\
\hline Fall from height & 6 & 9.4 \\
\hline Other & 2 & 3.1 \\
\hline Total & 64 & 100.0 \\
\hline
\end{tabular}




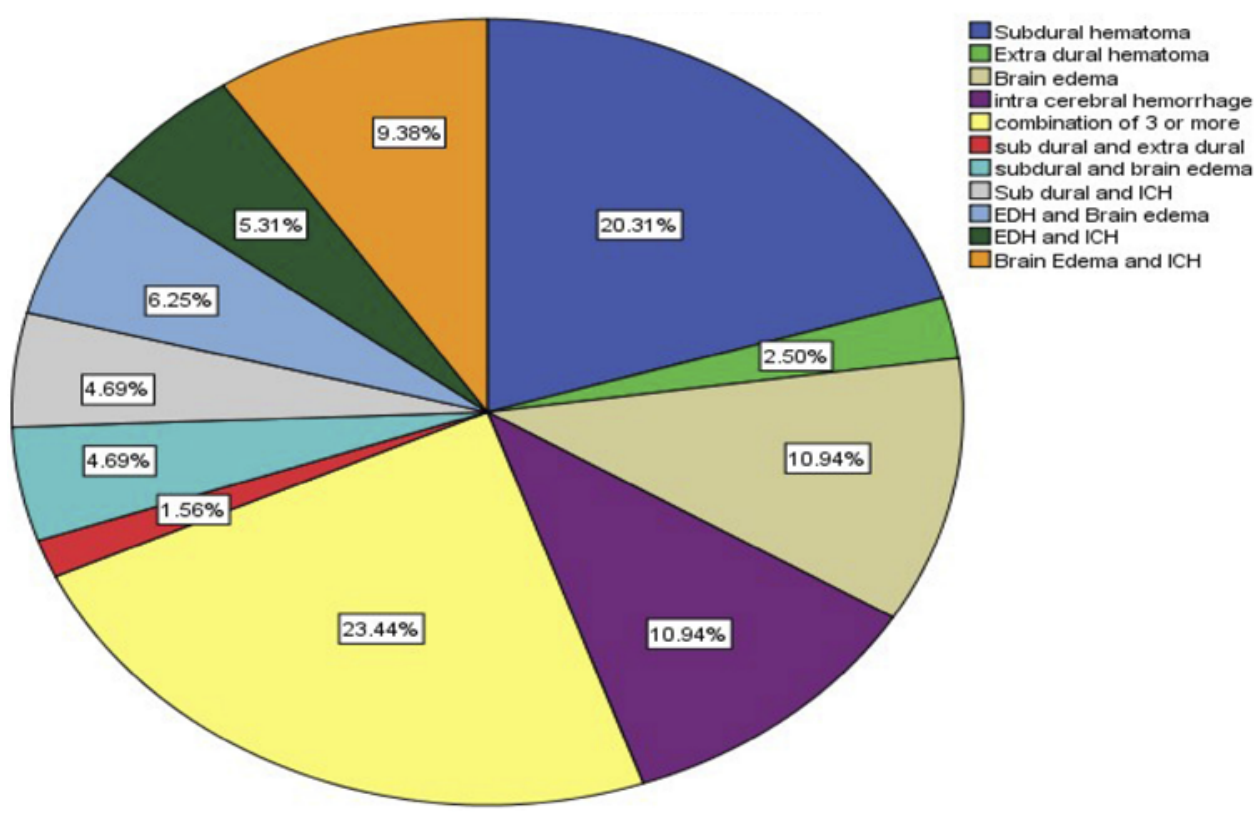

FIG. 2. Pie chart of intracranial pathology in patients with $\mathrm{TBI}$. EDH = extradural hematoma; $I C H=$ intracerebral hemorrhage.

in $7(10.9 \%)$, intracerebral hemorrhage in 7 (10.9\%), combinations of 3 or more pathologies in $15(23.4 \%)$, combined subdural and extradural hematoma in $1(1.6 \%)$, combined subdural hematoma and brain edema in $3(4.7 \%)$, combined subdural hematoma and intracerebral hemorrhage in $3(4.7 \%)$, combined extradural hematoma and brain edema in $4(6.3 \%)$, combined extradural hematoma and intracerebral hemorrhage in $3(4.7 \%)$, and combined brain edema and intracerebral hemorrhage in $6(9.4 \%)$ patients (Fig. 2).

The endpoint for assessment was the 3-month GOS score $^{22}$ with its 5 categories: 1 , dead; 2 , persistent vegetative state; 3 , severe disability; 4, moderate disability; and 5 , good recovery. Good cerebral function or recovery was defined as $\mathrm{GOS} \geq 4$. Of the 64 patients, $0 \%(\mathrm{n}=0)$ and $65.6 \%(n=42)$ presented with good functional status at admission and at final evaluation, respectively.

After 3 months of neurosurgical management, the outcome was characterized by $12.5 \%$ of deaths (GOS 1), $11.5 \%$ of persistent vegetative state (GOS 2), $10 \%$ of moderate disability (GOS 4), and $66 \%$ of good neurological functional state (GOS 5). Thus, at day 90, less than $15 \%$ of the patients who were still alive presented with severe disability or persistent vegetative state.

\section{Univariate Analysis and Optimal Cutoff Points to Discriminate Recovery of Neurological Function and Unchanged GCS Score}

The univariate risk of recovery of neurological functional status was computed using ROC curve methods to define optimal cutoff points of significant independent variables (Table 3, Fig. 3). There was no significant univariate association ( $\mathrm{p}>0.05$ ) between sex, serum IL-6, serum IL-10, and recovery of good function (results not shown). However, significant univariate correlates of recovery of good function (GOS $\geq 4$ ) were identified using optimal cutoffs to discriminate unchanged neurological status from recovery of good functional status by using ROC methods. Indeed, serum IL-1 $\beta$, serum MDA, serum SOD, serum TAC, CSF SOD, and CSF TAC were confirmed as either significant or important univariate correlates of recovery based on their prognostic performance (Table 3); the correlations for serum IL-1 $\beta$, serum SOD, and CSF TAC were not statistically significant $(\mathrm{p}=0.08)$. To discriminate between recovery and nonrecovery using the ROC methods, the area under the curve (AUC) and 95\% confidence interval (CI) were used.

According to the univariate analysis, the main fac-

TABLE 3. Optimal cutoff as defined by ROC curve analysis

\begin{tabular}{cccccccc}
\hline Marker & \multicolumn{1}{c}{ Cutoff } & AUC & $95 \% \mathrm{Cl}$ & SE & $\%$ Sensitivity & $\%$ Specificity & $p$ Value \\
\hline Serum IL-1 & $<35 \mathrm{pg} / \mathrm{ml}$ & 0.619 & $0.533-0.704$ & 0.043 & 66 & 57 & 0.08 \\
\hline Serum MDA & $<1.4 \mu \mathrm{mol} / \mathrm{L}$ & 0.653 & $0.567-0.738$ & 0.044 & 70 & 52 & $<0.001$ \\
\hline Serum SOD & $\geq 0.3 \mathrm{IU} / \mathrm{ml}$ & 0.573 & $0.475-0.671$ & 0.050 & 60 & 60 & 0.08 \\
\hline Serum TAC & $\geq 450 \mu \mathrm{mol} / \mathrm{L}$ & 0.662 & $0.566-0.757$ & 0.049 & 72.2 & 52 & $<0.0001$ \\
\hline CSF SOD & $\geq 0.3 \mathrm{IU} / \mathrm{ml}$ & 0.635 & $0.547-0.734$ & 0.045 & 63 & 52 & 0.002 \\
\hline CSF TAC & $\geq 300 \mu \mathrm{mol} / \mathrm{L}$ & 0.577 & $0.488-0.666$ & 0.045 & 70 & 50 & 0.083 \\
\hline
\end{tabular}




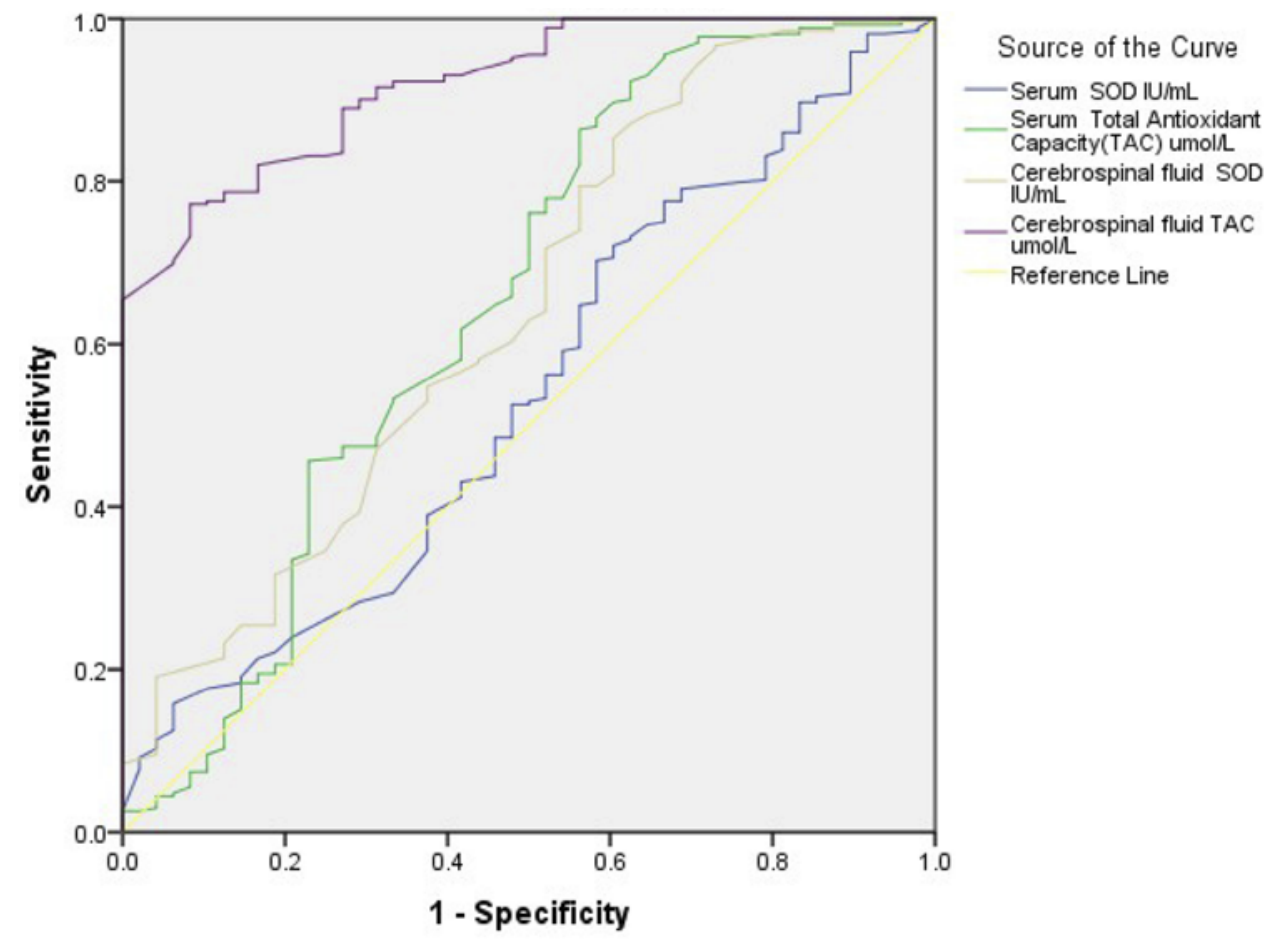

Diagonal segments are produced by ties.

FIG. 3. ROC curves for significant correlates of recovery of good functional status.

tors that strongly predicted recovery and improvement of functional status in patients with moderate to severe TBI included serum IL-1 $\beta$, serum MDA, serum SOD, serum TAC, CSF SOD, and CSF TAC (Tables 3 and 4), as was amplified by the calculated relative risk (Table 4).

Multivariate analysis was then performed to identify the most significant independent predictors of recovery, by using Cox regression analysis (Table 5) and stratified Kaplan-Meier curves (Figs. 4 and 5). In Cox regression analysis, after adjusting for serum SOD, serum TAC, serum IL-1 $\beta$, serum IL-10, and serum MDA, only the CSF SOD and CSF TAC remained as the most significant independent predictors of recovery of good functional status (Table 5). Indeed, the likelihood of recovery of good functional status-defined as GOS $\geq 4$-was multiplied in excess of $90 \%$ by both CSF SOD $\geq 0.3 \mathrm{IU} / \mathrm{ml}$ and CSF $\mathrm{TAC} \geq 300 \mu \mathrm{mol} / \mathrm{L}$ (Table 4).

The comparisons of the mean time to recovery of good functional status according to the log-rank test by stratification of CSF SOD (Fig. 4) and CSF TAC (Fig. 5) were obtained by the Kaplan-Meier curves.

\section{Kaplan-Meier Analysis of CSF SOD as an Indicator of Recovery}

Based on Kaplan-Meier analysis of the CSF SOD activity, the cumulative proportion of patients with CSF SOD activity $\geq 0.3 \mathrm{IU} / \mathrm{ml}$ who recovered good functional status was $95.7 \%$, with a mean time to recovery of $34 \pm 1.9$ days. This was statistically significant $(\mathrm{p}<0.0001$ by the logrank Mantel-Cox test) when compared with the proportion of patients with CSF SOD activity $<0.3 \mathrm{IU} / \mathrm{ml}$ who
TABLE 4. Summary of calculated significant association between correlates and recovery of good functional status

\begin{tabular}{|c|c|c|c|c|c|}
\hline $\begin{array}{l}\text { Variable of } \\
\text { Interest }\end{array}$ & $\begin{array}{c}\% \text { w/ } \\
\text { Recovery } \\
\text { of Good } \\
\text { Functional } \\
\text { Status (no.) }\end{array}$ & $\begin{array}{c}\% \text { w/ } \\
\text { Disability } \\
\text { (no.) }\end{array}$ & $\begin{array}{c}\text { Relative } \\
\text { Risk }\end{array}$ & $\begin{array}{c}95 \% \\
\mathrm{Cl}\end{array}$ & $\begin{array}{c}p \\
\text { Value }\end{array}$ \\
\hline \multicolumn{6}{|l|}{ Serum IL-1ß } \\
\hline$<35 \mathrm{pg} / \mathrm{ml}$ & $94.7(36)$ & $5.3(2)$ & 1.4 & $1.2-1.5$ & $<0.0001$ \\
\hline$\geq 35 \mathrm{pg} / \mathrm{ml}$ & $69.2(18)$ & $30.8(8)$ & & & \\
\hline \multicolumn{6}{|l|}{ Serum MDA } \\
\hline$<1.4 \mu \mathrm{mol} / \mathrm{L}$ & $94.4(34)$ & $5.6(2)$ & 1.4 & $1.2-1.5$ & $<0.0001$ \\
\hline$\geq 1.4 \mu \mathrm{mol} / \mathrm{L}$ & $71.4(20)$ & $28.6(8)$ & & & \\
\hline \multicolumn{6}{|l|}{ Serum SOD } \\
\hline$\geq 0.3 \mathrm{IU} / \mathrm{ml}$ & $93.3(42)$ & $6.7(3)$ & 1.5 & $1.3-1.8$ & $<0.0001$ \\
\hline$<0.3 \mathrm{IU} / \mathrm{ml}$ & $57.9(11)$ & $42.1(8)$ & & & \\
\hline \multicolumn{6}{|l|}{ Serum TAC } \\
\hline$\geq 450 \mu \mathrm{mol} / \mathrm{L}$ & $92.5(37)$ & $7.5(3)$ & 1.4 & $1.2-1.6$ & $<0.0001$ \\
\hline$<450 \mu \mathrm{mol} / \mathrm{L}$ & $66.7(16)$ & $33.3(8)$ & & & \\
\hline \multicolumn{6}{|l|}{ CSF SOD } \\
\hline$\geq 0.3 \mathrm{IU} / \mathrm{ml}$ & $95.7(44)$ & $4.3(2)$ & 1.7 & $1.4-2$ & $<0.0001$ \\
\hline$<0.3 \mathrm{lU} / \mathrm{ml}$ & $55.6(10)$ & $44.4(8)$ & & & \\
\hline \multicolumn{6}{|l|}{ CSF TAC } \\
\hline$\geq 300 \mu \mathrm{mol} / \mathrm{L}$ & $95.5(42)$ & $4.5(2)$ & 1.5 & $1.3-1.8$ & $<0.0001$ \\
\hline$<300 \mu \mathrm{mol} / \mathrm{L}$ & $60(12)$ & $40(8)$ & & & \\
\hline
\end{tabular}




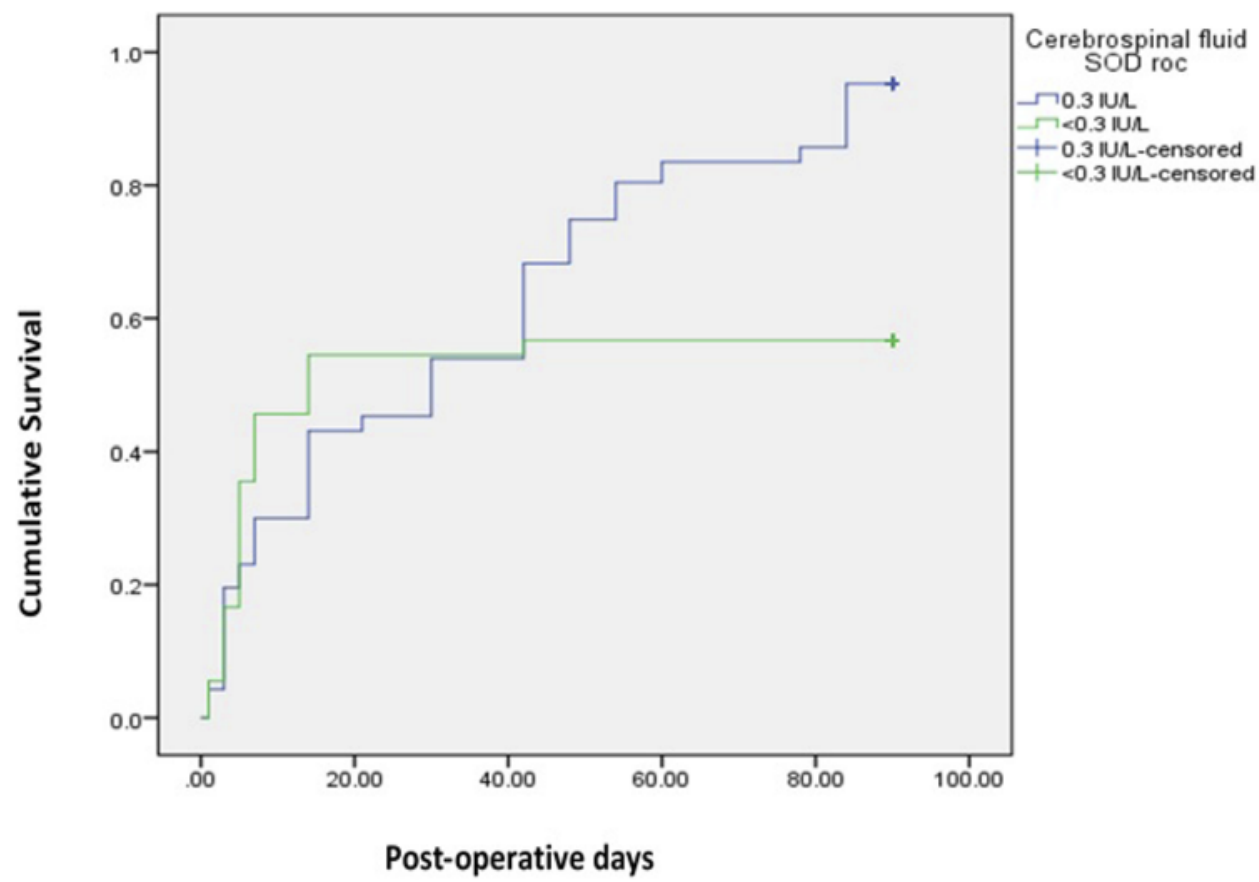

FIG. 4. Kaplan-Meier curves for CSF SOD in TBI.

recovered to $\mathrm{GOS} \geq 4$ (55.6\%, with mean time to recovery of $43 \pm 4.4$ days). Values for continuous variables are expressed as the mean \pm SD throughout.

\section{Kaplan-Meier Analysis of CSF TAC as an Indicator of Recovery}

Kaplan-Meier analysis was used to estimate the survival of patients based on the biomarkers. The cumulative proportion of patients with CSF TAC $\geq 300 \mu \mathrm{mol} / \mathrm{L}$ surviving and recovering to GOS $\geq 4$ was $95.5 \%$, with a mean time to recovery of $34.6 \pm 1.97$ days. This is significant when compared (log-rank Mantel-Cox test, $\mathrm{p}<0.001$ ) with the cumulative proportion of patients with CSF TAC $<300$ $\mu \mathrm{mol} / \mathrm{L}$ who would recover $(60 \%$, mean time to recovery $41.4 \pm 4.03$ days).

\section{Discussion}

As in previous South African studies, assaults were a predominant mechanism of injury in our study population. This is unlike the findings in North American studies, in which motor vehicle accidents and falls are the most common causes of TBI. ${ }^{10,44,50}$

In this study, we describe the impact of TBI and neurosurgical management on clinical and biomarker profiles to predict the likelihood of recovery as defined by the GOS score at 3 months. We attempt to provide an objective assessment of the likely outcome by discriminating recovery $(\mathrm{GOS} \geq 4)$ from nonrecovery (poor outcomes) (GOS $\leq 3$ ) after moderate to severe TBI.

The most significant prognostic information was observed from CSF TAC and SOD activity. None of these factors have been considered in prognostic models such as the International Mission for Prognosis and Clinical Trials in Traumatic Brain Injury (IMPACT) and Corti- costeroid Randomisation After Significant Head Injury (CRASH-1) ${ }^{29,47}$ Indeed, these two characteristics have not been previously studied to determine any relationship with clinical outcomes in TBI.

Following neurosurgical intervention and management, some patients did not recover and were observed to have had an unchanged ("maintained") neurological functional status $(\mathrm{GOS} \leq 3)$ by day 90 . Univariate correlates of recovery by ROC curve analysis defined thresholds for serum IL-1 $\beta$, serum MDA (by TBARS assay), and serum and CSF SOD and TAC.

From this research it is evident that high levels of IL-1 $\beta$ are associated with lack of recovery and poor outcomes after TBI among these patients. This is most likely to be related to the potent proinflammatory effects of IL-1 $\beta$, which lead to an increase in volume of hemorrhagic contusions and brain edema. These pathophysiological changes in TBI result in poor clinical outcomes as manifested by the low GOS score. ${ }^{18,43}$ Various studies have been done to determine the prognostic significance of some biomarkers, including the calcium-binding protein (S100B) and neuron-specific enolase as biomarkers in TBI. No universal consensus has been reached to define the role of these biomarkers in predicting outcomes, due to their low specificity and the small sample sizes used. ${ }^{40,53}$

Analysis using ROC methods revealed that IL- $1 \beta$ levels $\geq 35 \mathrm{pg} / \mathrm{ml}$ were associated with poor clinical outcomes $(\mathrm{GOS} \leq 3)$. The proinflammatory effects of IL-1 $\beta$ aggravate the pathological changes in TBI and affect the patient's capacity for survival and recovery. The association of elevated serum IL-1 $\beta$, a proinflammatory cytokine with poor clinical outcomes, has also been demonstrated in other studies. ${ }^{6,13,46,56}$ Indeed, the impact of IL-1 $\beta$ on survival and recovery revealed in this study has also been demonstrated in various other studies. ${ }^{12}$ 


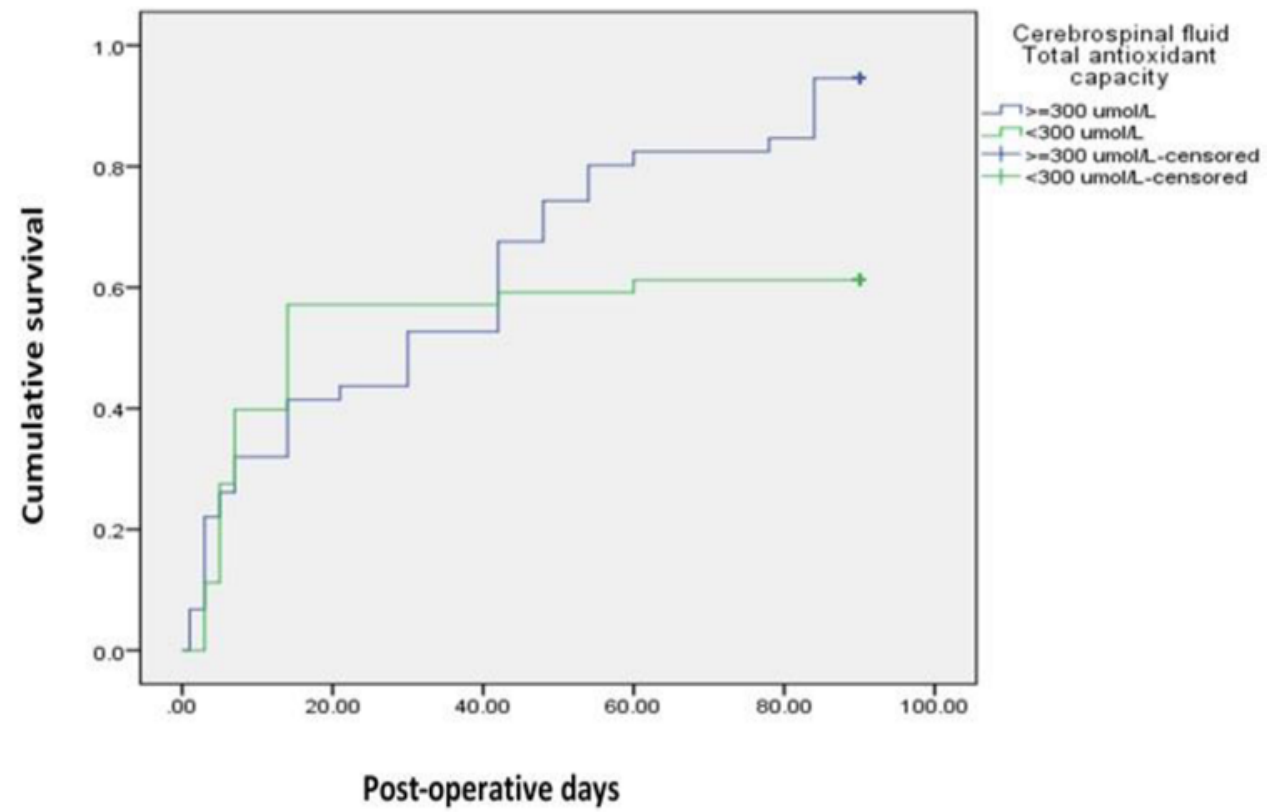

FIG. 5. Kaplan-Meier curves for CSF TAC in TBI.

This study identifies high levels of MDA $(\geq 1.4 \mu \mathrm{mol} / \mathrm{L}$; $\mathrm{p}=0.041)$ as associated with decreased survival and poor outcomes $(\mathrm{GOS} \leq 3)$ in patients with TBI. ROC curve analysis identified MDA as a significant predictor of recovery (AUC 0.653 ; p < 0.001; sensitivity 70\%, specificity 52\%) after TBI. Based on these findings, levels of MDA, a byproduct of lipid peroxidation, can be used to prognosticate outcomes in TBI. Early after TBI oxidative stress changes occur, leading to increased lipid peroxidation and decreased enzymatic antioxidant activities, which can influence clinical outcomes in these patients..$^{16,31}$ These findings are further supported by the Kaplan-Meier analysis, which revealed that elevated MDA levels $(\geq 1.4 \mu \mathrm{mol} / \mathrm{L})$ are associated with decreased survival and increased fatality.

Unlike previous studies on the role of biomarkers in TBI, this research shows the chronobiological changes in biomarkers over several days. In this study, although the levels of MDA were high immediately following trauma and admission, prompt neurosurgical intervention and ICU management led to a progressive decline in the levels over several days and to a reduction in the oxidative stress imbalance among our patients. The impact of the reduction in MDA levels below the threshold value on the recovery of our patients highlighted the predictive significance of this biomarker. As has been documented in other studies, MDA is a significant biomarker of lipid peroxidation and oxidative stress. ${ }^{36}$ The increased lipid peroxidation and elevated MDA levels were associated with a decrease in enzymatic antioxidant activity, which may have led to poor clinical outcomes in our patients. This association of increased lipid peroxidation with poor outcomes has also been shown in other studies. ${ }^{16,31}$

The enzymatic antioxidant activity of SOD is necessary to counter the prooxidant response and to correct the oxidative stress imbalance in TBI, and by so doing, SOD aids in neurological recovery. ${ }^{19,60}$ ROC curves identified
CSF SOD activity $\geq 0.3 \mathrm{IU} / \mathrm{ml}$ as being correlated with recovery, with sufficient power to discriminate recovery from nonrecovery (AUC $0.635 ; \mathrm{p}=0.002$; sensitivity $63 \%$, specificity 52\%). In Kaplan-Meier analysis, when CSF SOD activity was $\geq 0.3 \mathrm{IU} / \mathrm{ml}$, more patients $(95.7 \%)$ had a greater probability of recovery $(\mathrm{p}<0.0001)$. Additionally, the recovery period was shorter (34 \pm 1.9 days) than when the CSF SOD activity was $<0.3 \mathrm{IU} / \mathrm{ml}(55.6 \%$ over $43 \pm$ 4.4 days). The chance for survival and recovery of good functional status was shown to be 4 times greater when the CSF SOD activity was $\geq 0.3 \mathrm{IU} / \mathrm{ml}$.

Free radicals generated during oxidative stress response cause ischemic cerebral damage and may result in reduced patient survival and poor outcomes. Increased antioxidant biomarkers including SOD in TBI scavenge the reactive species and correct the oxidative stress imbalance and inflammatory response to get better clinical outcomes. ${ }^{23,35}$ Our study demonstrates these observations and shows that the resolution (elevation) of antioxidant biomarkers including SOD and total antioxidant activity in CSF significantly impacts clinical outcomes.

TABLE 5. Independent predictors of recovery by Cox regression analysis

\begin{tabular}{cccccc}
\hline Variable & B Statistic & SE & $\begin{array}{c}\text { Wald } \\
\text { Test }\end{array}$ & HR $(95 \%$ Cl $)$ & p Value \\
\hline CSF TAC & & & & & \\
\hline$\geq 300 \mu \mathrm{mol} / \mathrm{L}$ & 0.363 & 0.180 & 4.085 & $1.4(1.01-2.1)$ & 0.043 \\
\hline$<300 \mu \mathrm{mol} / \mathrm{L}$ & & & Referent & 1 & \\
\hline CSF SOD & & & & & \\
\hline$\geq 0.3 \mathrm{IU} / \mathrm{ml}$ & 0.471 & 0.189 & 6.224 & $1.6(1.1-2.3)$ & $<0.01$ \\
\hline$<0.3 \mathrm{IU} / \mathrm{ml}$ & & & Referent & 1 & \\
\hline
\end{tabular}


ROC curve analysis furthermore identified better clinical outcomes when serum TAC was $\geq 450 \mu \mathrm{mol} / \mathrm{L}$ (AUC 0.662; $\mathrm{p}<0.0001$ ). However, analysis of CSF TAC showed that the optimal cutoff value for recovery was $\geq 300 \mu \mathrm{mol} / \mathrm{L}$ (AUC 0.577), which defines the important role of antioxidants in averting the oxidative stress imbalance. Further analysis using Cox regression models defined CSF TAC as a major determinant of good outcomes in TBI (hazard ratio [HR] 1.4, 95\% CI 1.01-2.1; $\mathrm{p}=0.043$ ) (Table 5).

Additionally, Kaplan-Meier analysis showed that when CSF TAC levels were $\geq 300 \mu \mathrm{mol} / \mathrm{L}$, the cumulative proportion of patients surviving was $95.5 \%$, with a shorter time to recovery ( $34.6 \pm 1.97$ days) when compared with levels $<300 \mu \mathrm{mol} / \mathrm{L}$, where the proportion of patients recovering was smaller (60\%) and the time to recovery was prolonged (41.4 \pm 4 days). Indeed, various studies show that antioxidant defenses can prolong survival, enhance recovery, and reduce the destructive effects of free radicals and oxidant factors. ${ }^{34,35}$ Thus, both Kaplan-Meier and Cox regression analysis demonstrate that the resolution and improved antioxidant activity of CSF SOD and CSF TAC not only shorten the time to recovery but also result in an increased proportion of patients with better outcomes $(\mathrm{GOS} \geq 4)$.

Thus, in multivariate analysis an elevation in CSF TAC and CSF SOD activity was independently associated with recovery of good functional status $(\mathrm{GOS} \geq 4)$. The findings in this study reveal that antioxidant factors, as defined by the CSF TAC levels and SOD activity, are important in the recovery of patients with moderate to severe TBI. Multivariate Cox regression analysis revealed that recovery $(\mathrm{GOS} \geq 4)$ in TBI was significantly dependent on factors such as increased antioxidant function, manifested by increased CSF SOD $\geq 0.3 \mathrm{IU} / \mathrm{ml}$ (HR 1.6, 95\% CI 1.1-2.3; $\mathrm{p}<0.01)$ and increased CSF TAC $\geq 300 \mu \mathrm{mol} / \mathrm{L}$ (HR 1.4, 95\% CI 1.01-2.1; $\mathrm{p}=0.043$ ).

This study reveals that the resolution in levels of antioxidants as evidenced by the CSF SOD and CSF TAC is more predictive of functional recovery. The study further justifies the important role of endogenous antioxidants in functional recovery. The impact of antioxidant and antiinflammatory biomarkers in correcting the oxidative stress imbalance, BBB dysfunction, and cerebral autoregulation has been documented in various other studies. ${ }^{5}$

Studies on the role of calcium-binding protein (S100B) and neuron-specific enolase show that elevated levels of these biomarkers may be predictive of poor outcomes in patients with TBI. ${ }^{11,27}$ Our investigation is a comprehensive study that relates the trends of biomarker profiles over several days to the clinical recovery of patients with moderate to severe TBI. As illustrated in other studies, this research defines the role of antioxidants in reversing the destructive effects of free radicals. ${ }^{34,35}$

\section{Limitations of the Study and Future Perspectives}

This sample size was relatively small and the study was conducted in a single institution; therefore, institutional bias may be a valid limitation. It would be preferable to conduct a larger, multicenter, institutional study that evaluates the impact of replenishment of antioxidants and relates it to clinical outcomes in patients with moderate to severe TBI.

\section{Conclusions}

Independent predictors of recovery in patients with moderate to severe TBI include CSF SOD and CSF TAC. An elevation in the antioxidant levels in the CSF was associated with better clinical outcomes. Although other studies have evaluated the role of biomarkers in TBI, none of them reviewed the trends in these biomarkers and their impact on survival, as has been demonstrated in this study.

\section{Acknowledgments}

I (K.D.M.) would like to thank the Walter Sisulu University research office for funding this study. This funding was granted to me during my Doctor of Philosophy in Health Sciences studies.

\section{References}

1. Allan SM, Rothwell NJ: Cytokines and acute neurodegeneration. Nat Rev Neurosci 2:734-744, 2001

2. Andelic N, Hammergren N, Bautz-Holter E, Sveen U, Brunborg C, Røe C: Functional outcome and health-related quality of life 10 years after moderate-to-severe traumatic brain injury. Acta Neurol Scand 120:16-23, 2009

3. Arimoto T, Choi DY, Lu X, Liu M, Nguyen XV, Zheng N, et al: Interleukin-10 protects against inflammation-mediated degeneration of dopaminergic neurons in substantia nigra. Neurobiol Aging 28:894-906, 2007

4. Barone FC, Price WJ, White RF, Willette RN, Feuerstein GZ: Genetic hypertension and increased susceptibility to cerebral ischemia. Neurosci Biobehav Rev 16:219-233, 1992

5. Batinic-Haberle I, Rajic Z, Tovmasyan A, Reboucas JS, Ye $\mathrm{X}$, Leong KW, et al: Diverse functions of cationic Mn(III) N-substituted pyridylporphyrins, recognized as SOD mimics. Free Radic Biol Med 51:1035-1053, 2011

6. Chiaretti A, Genovese O, Aloe L, Antonelli A, Piastra M, Polidori G, et al: Interleukin 1beta and interleukin 6 relationship with paediatric head trauma severity and outcome. Childs Nerv Syst 21:185-194, 2005

7. Demetriades D, Kuncir E, Murray J, Velmahos GC, Rhee P, Chan L: Mortality prediction of head Abbreviated Injury Score and Glasgow Coma Scale: analysis of 7,764 head injuries. J Am Coll Surg 199:216-222, 2004

8. DeWitt DS, Prough DS: Traumatic cerebral vascular injury: the effects of concussive brain injury on the cerebral vasculature. J Neurotrauma 20:795-825, 2003

9. Doherty DE, Downey GP, Worthen GS, Haslett C, Henson PM: Monocyte retention and migration in pulmonary inflammation. Requirement for neutrophils. Lab Invest 59:200213,1988

10. Domingo Z, Peter JC, de Villiers JC: Low-velocity penetrating craniocerebral injury in childhood. Pediatr Neurosurg 21:45-49, 1994

11. Egea-Guerrero JJ, Revuelto-Rey J, Murillo-Cabezas F, Muñoz-Sánchez MA, Vilches-Arenas A, Sánchez-Linares P, et al: Accuracy of the $S 100 \beta$ protein as a marker of brain damage in traumatic brain injury. Brain Inj 26:76-82, 2012

12. Egerod I, Jensen MB, Herling SF, Welling KL: Effect of an analgo-sedation protocol for neurointensive patients: a twophase interventional non-randomized pilot study. Crit Care 14:R71, 2010

13. Fan L, Young PR, Barone FC, Feuerstein GZ, Smith DH, McIntosh TK: Experimental brain injury induces expression of interleukin-1 beta mRNA in the rat brain. Brain Res Mol Brain Res 30:125-130, 1995

14. Feng Q, Wang YI, Yang Y: Neuroprotective effect of interleukin-6 in a rat model of cerebral ischemia. Exp Ther Med 9:1695-1701, 2015 
15. Foreman BP, Caesar RR, Parks J, Madden C, Gentilello LM, Shafi S, et al: Usefulness of the abbreviated injury score and the injury severity score in comparison to the Glasgow Coma Scale in predicting outcome after traumatic brain injury. J Trauma 62:946-950, 2007

16. Gaetani P, Marzatico F, Rodriguez y Baena R, Pacchiarini L, Viganò T, Grignani G, et al: Arachidonic acid metabolism and pathophysiologic aspects of subarachnoid hemorrhage in rats. Stroke 21:328-332, 1990

17. Goodman JC, Robertson CS, Grossman RG, Narayan RK: Elevation of tumor necrosis factor in head injury. J Neuroimmunol 30:213-217, 1990

18. Hopkins SJ, Rothwell NJ: Cytokines and the nervous system. I: Expression and recognition. Trends Neurosci 18:83-88, 1995

19. Hudome S, Palmer C, Roberts RL, Mauger D, Housman C, Towfighi J: The role of neutrophils in the production of hypoxic-ischemic brain injury in the neonatal rat. Pediatr Res 41:607-616, 1997

20. Hukkelhoven CW, Steyerberg EW, Habbema JD, Farace E, Marmarou A, Murray GD, et al: Predicting outcome after traumatic brain injury: development and validation of a prognostic score based on admission characteristics. J Neurotrauma 22:1025-1039, 2005

21. Ikeda Y, Anderson JH, Long DM: Oxygen free radicals in the genesis of traumatic and peritumoral brain edema. Neurosurgery 24:679-685, 1989

22. Jennett B, Bond M: Assessment of outcome after severe brain damage. Lancet 1:480-484, 1975

23. Juurlink BH: Response of glial cells to ischemia: roles of reactive oxygen species and glutathione. Neurosci Biobehav Rev 21:151-166, 1997

24. Köller M, Clasbrummel B, Kollig E, Hahn MP, Muhr G: Major injury induces increased production of interleukin-10 in human granulocyte fractions. Langenbecks Arch Surg 383:460-465, 1998

25. Kontos HA, Wei EP, Povlishock JT, Christman CW: Oxygen radicals mediate the cerebral arteriolar dilation from arachidonate and bradykinin in cats. Circ Res 55:295-303, 1984

26. Kretzschmar M, Pfeiffer L, Schmidt C, Schirrmeister W: Plasma levels of glutathione, alpha-tocopherol and lipid peroxides in polytraumatized patients; evidence for a stimulating effect of TNF alpha on glutathione synthesis. Exp Toxicol Pathol 50:477-483, 1998

27. Lesko MM, O'Brien SJ, Childs C, Bouamra O, Rainey T, Lecky F: Comparison of several prognostic tools in traumatic brain injury including S100B. Brain Inj 28:987-994, 2014

28. Lisinski TJ, Furie MB: Interleukin-10 inhibits proinflammatory activation of endothelium in response to Borrelia burgdorferi or lipopolysaccharide but not interleukin-1beta or tumor necrosis factor alpha. J Leukoc Biol 72:503-511, 2002

29. Maas AI, Marmarou A, Murray GD, Teasdale SG, Steyerberg EW: Prognosis and clinical trial design in traumatic brain injury: the IMPACT study. J Neurotrauma 24:232-238, 2007

30. Marshall LF, Marshall SB, Klauber MR, Van Berkum Clark M, Eisenberg H, Jane JA, et al: The diagnosis of head injury requires a classification based on computed axial tomography. J Neurotrauma 9 (Suppl 1):S287-S292, 1992

31. Marzatico F, Gaetani P, Cafè C, Spanu G, Rodriguez y Baena $\mathrm{R}$ : Antioxidant enzymatic activities after experimental subarachnoid hemorrhage in rats. Acta Neurol Scand 87:62-66, 1993

32. Masson F, Thicoipe M, Aye P, Mokni T, Senjean P, Schmitt $\mathrm{V}$, et al: Epidemiology of severe brain injuries: a prospective population-based study. J Trauma 51:481-489, 2001

33. Matzinger P: The danger model: a renewed sense of self. Science 296:301-305, 2002

34. McCord JM: Human disease, free radicals, and the oxidant/ antioxidant balance. Clin Biochem 26:351-357, 1993
35. McCord JM: Oxygen-derived free radicals. New Horiz 1:70_ 76, 1993

36. Meagher EA, FitzGerald GA: Indices of lipid peroxidation in vivo: strengths and limitations. Free Radic Biol Med 28:1745-1750, 2000

37. Morganti-Kossmann MC, Rancan M, Otto VI, Stahel PF, Kossmann T: Role of cerebral inflammation after traumatic brain injury: a revisited concept. Shock 16:165-177, 2001

38. Nathan C: Points of control in inflammation. Nature 420:846-852, 2002

39. Oppenheim JJ, Zachariae CO, Mukaida N, Matsushima K: Properties of the novel proinflammatory supergene "intercrine" cytokine family. Annu Rev Immunol 9:617-648, 1991

40. Papa L, Lewis LM, Silvestri S, Falk JL, Giordano P, Brophy GM, et al: Serum levels of ubiquitin C-terminal hydrolase distinguish mild traumatic brain injury from trauma controls and are elevated in mild and moderate traumatic brain injury patients with intracranial lesions and neurosurgical intervention. J Trauma Acute Care Surg 72:1335-1344, 2012

41. Riva-Depaty I, Fardeau C, Mariani J, Bouchaud C, DelhayeBouchaud N: Contribution of peripheral macrophages and microglia to the cellular reaction after mechanical or neurotoxin-induced lesions of the rat brain. Exp Neurol 128:77-87, 1994

42. Rosenberg AL: Recent innovations in intensive care unit riskprediction models. Curr Opin Crit Care 8:321-330, 2002

43. Rothwell NJ, Hopkins SJ: Cytokines and the nervous system II: Actions and mechanisms of action. Trends Neurosci 18:130-136, 1995

44. Rutland-Brown W, Langlois JA, Thomas KE, Xi YL: Incidence of traumatic brain injury in the United States, 2003. J Head Trauma Rehabil 21:544-548, 2006

45. Schlag G, Redl H: Mediators of injury and inflammation. World J Surg 20:406-410, 1996

46. Shiozaki T, Hayakata T, Tasaki O, Hosotubo H, Fuijita K, Mouri T, et al: Cerebrospinal fluid concentrations of anti-inflammatory mediators in early-phase severe traumatic brain injury. Shock 23:406-410, 2005

47. Subaiya S, Roberts I, Komolafe E, Perel P: Predicting intracranial hemorrhage after traumatic brain injury in low and middle-income countries: a prognostic model based on a large, multi-center, international cohort. BMC Emerg Med 12:17, 2012

48. Teasdale G, Jennett B: Assessment of coma and impaired consciousness. A practical scale. Lancet 2:81-84, 1974

49. Thorburne SK, Juurlink BH: Low glutathione and high iron govern the susceptibility of oligodendroglial precursors to oxidative stress. J Neurochem 67:1014-1022, 1996

50. Thurman DJ, Alverson C, Dunn KA, Guerrero J, Sniezek JE: Traumatic brain injury in the United States: A public health perspective. J Head Trauma Rehabil 14:602-615, 1999

51. Timmons SD, Bee T, Webb S, Diaz-Arrastia RR, Hesdorffer $\mathrm{D}$ : Using the abbreviated injury severity and Glasgow Coma Scale scores to predict 2 -week mortality after traumatic brain injury. J Trauma 71:1172-1178, 2011

52. Todo H, Ohta S, Wang J, Ichikawa H, Ohue S, Kumon Y, et al: Impairment in biochemical level of arterial dilative capability of a cyclic nucleotides-dependent pathway by induced vasospasm in the canine basilar artery. J Cereb Blood Flow Metab 18:808-817, 1998

53. Topolovec-Vranic J, Pollmann-Mudryj MA, Ouchterlony D, Klein D, Spence J, Romaschin A, et al: The value of serum biomarkers in prediction models of outcome after mild traumatic brain injury. J Trauma 71 (5 Suppl 1):S478-S486, 2011

54. Vincent JL, Ferreira F, Moreno R: Scoring systems for assessing organ dysfunction and survival. Crit Care Clin 16:353-366, 2000 
55. Williams TI, Lovell MA, Lynn BC: Analysis of derivatized biogenic aldehydes by LC tandem mass spectrometry. Anal Chem 77:3383-3389, 2005

56. Winter CD, Iannotti F, Pringle AK, Trikkas C, Clough GF, Church MK: A microdialysis method for the recovery of IL-1beta, IL-6 and nerve growth factor from human brain in vivo. J Neurosci Methods 119:45-50, 2002

57. Xing Z, Gauldie J, Cox G, Baumann H, Jordana M, Lei XF, et al: IL-6 is an antiinflammatory cytokine required for controlling local or systemic acute inflammatory responses. $\mathbf{J}$ Clin Invest 101:311-320, 1998

58. Yin Z, Braun J, Neure L, Wu P, Eggens U, Krause A, et al: $T$ cell cytokine pattern in the joints of patients with Lyme arthritis and its regulation by cytokines and anticytokines. Arthritis Rheum 40:69-79, 1997

59. Yin Z, Braun J, Neure L, Wu P, Liu L, Eggens U, et al: Crucial role of interleukin-10/interleukin-12 balance in the regulation of the type $2 \mathrm{~T}$ helper cytokine response in reactive arthritis. Arthritis Rheum 40:1788-1797, 1997

60. Zuccarello M, Boccaletti R, Romano A, Rapoport RM: Endothelin $\mathrm{B}$ receptor antagonists attenuate subarachnoid hemorrhage-induced cerebral vasospasm. Stroke 29:1924-1929, 1998

\section{Disclosures}

The authors report no conflict of interest concerning the materials or methods used in this study or the findings specified in this paper.

\section{Author Contributions}

Conception and design: Muballe. Acquisition of data: Muballe. Analysis and interpretation of data: Muballe. Drafting the article: Muballe. Critically revising the article: Muballe. Reviewed submitted version of manuscript: Muballe. Approved the final version of the manuscript on behalf of all authors: Muballe. Statistical analysis: Longo-Mbenza. Administrative/technical/material support: Iputo. Study supervision: Sewani-Rusike, Longo-Mbenza.

\section{Correspondence}

Kadhaya David Muballe: Walter Sisulu University, Mthatha, Eastern Cape Province, South Africa.kmuballe@yahoo.co.uk. 